Research Article

\title{
Species Diversity and Damage Incidence of Termites (Isoptera) in different Agro-ecological Zones of Khyber Pakhtunkhwa, Pakistan
}

\author{
Maid Zaman ${ }^{1 *}$, Imtiaz Ali Khan ${ }^{1}$, Amjad Usman ${ }^{1}$ and Ahmad-Ur-Rahman Saljoqi ${ }^{2}$
}

${ }^{1}$ Department of Entomology, Faculty of Crop Protection Sciences, The University of Agriculture Peshawar, Pakistan; ${ }^{2}$ Department of Plant Protection, Faculty of Crop Protection Sciences, The University of Agriculture Peshawar, Pakistan.

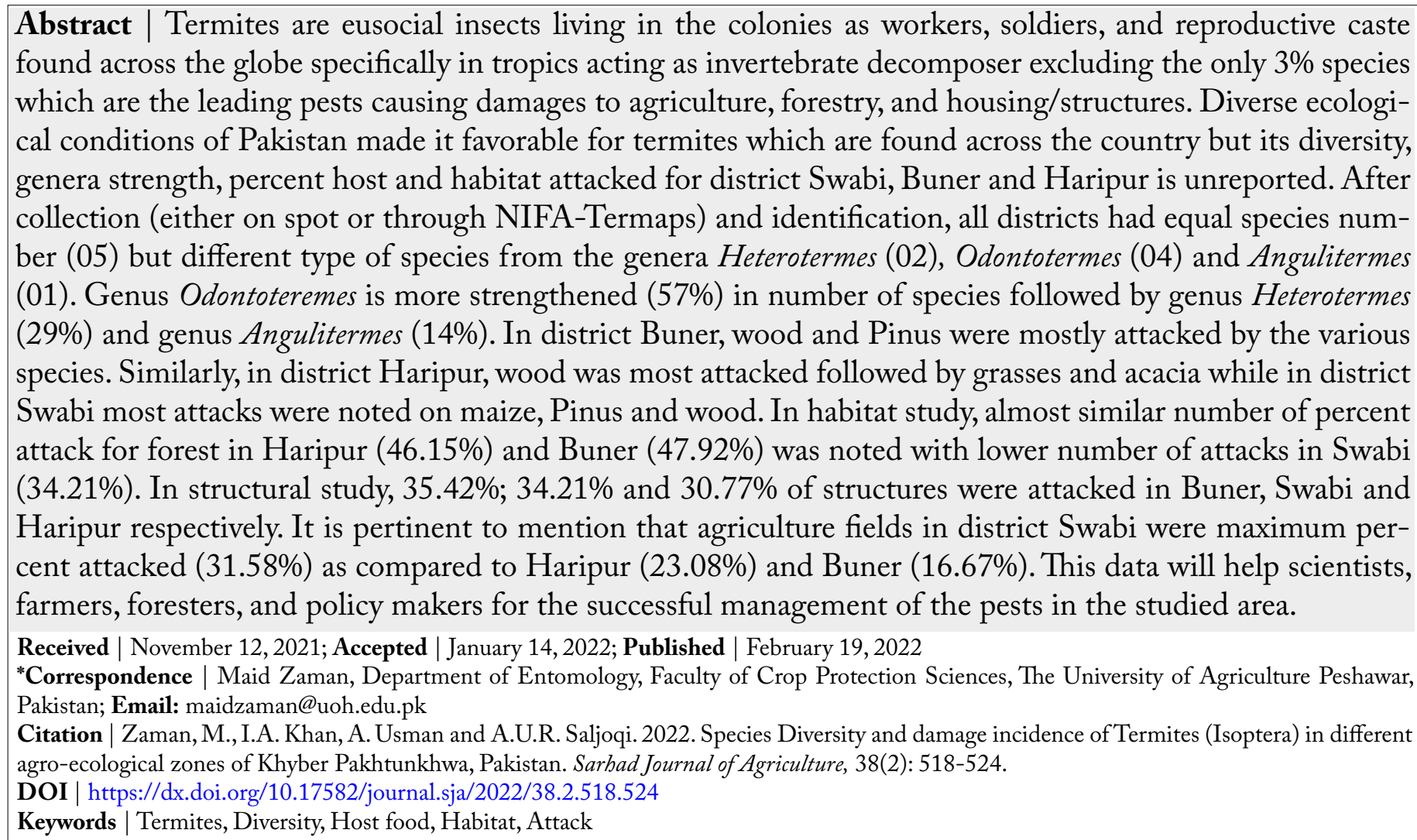

\section{Introduction}

$\mathrm{T}$ ermites (Isoptera) are divided into seven families and are known for their social behavior. They are eusocial insects (Hickey, 2006; Khan et al.,2015) living in the colonies as workers, soldiers, and reproductive caste. There are 80-to-90\% (Ahmed and French, 2008) workers in a colony which perform foraging activities and construction of galleries (Randall, 2000;
Hickey, 2006; Miller, 2010; Khan et al., 2015) and cleaning. Soldiers play a key role in the identification of species and colony defense. They are unable to eat and are fed by workers through trophallaxis, which is also a source of communication (Hickey, 2006). Third one is the reproductive caste (King, Queen, primary and secondary reproductive) responsible for reproduction (Randall, 2000; Hickey, 2006; Ahmed and French, 2008). Subterranean termites, damp wood 
termites and dry wood termites are the types of termites, which differ from each other based on character variations including nesting behavior (Randall, 2000) and ecology.

Naturally, termites spread to vast range of terrestrial environment specifically in tropics, acting as a major invertebrate decomposer (Eggleton, 2000). Although some sub-tropical species are of less ecological importance, but their economic importance cannot be neglected in case of their destruction in the urban environment. In tropics, termites are the leading pests in agriculture, forestry, and housing (Kirton, 2005). Some of the species contribute to ecosystem processes, carbon and nitrogen cycles, but they are well known for their economic importance (Ahmed et al., 2006). In case of subterranean termites, moist structures are the source of providing shelter (Hickey, 2006).

A total of 2650 is globally known species in which only 300 species are considered as a pest (Kambhampati and Eggleton, 2000). Similarly, Jones et al. (2005) reported that only 3\% species are responsible for damages to buildings and crops. Calculating percent crop losses in India i.e. 15-25\% in maize crop with a total of 35.12 million US dollars per annum. While in Southern Africa, 03-100\% crop losses has been reported with unknown actual economic losses per annum. Similarly, $42.7 \%$ for Brazil, $80-90 \%$ for China, $53.2 \%$ for Spain and 70\% residential, 20\% industrial and 10\% commercial building damages has been reported for Malaysia. Economic losses of 248.68292.79, 8-10, 95.24, 1000, 313 and 800 million US dollars per annum are reported for China, Malaysia, Australia, USA, Europe, and Japan respectively (Verma, 2009; Ghaly and Edward, 2011).

Considering the diverse ecological region, geological history, diverse latitude spreading, and high-altitude ranges of Pakistan, it is well founded proof about rich biodiversity in the region. Referring Akhtar (1972), the termite diversity in Pakistan has been failed to get considerable attraction for investigation since 1972. Certain termites species are beneficial in the forest by recycling the dead wood material, but some are destructive as Salihah et al. (2012) had reported there damages in structure/buildings, agriculture crops and forest plantation excluding district Swabi, Buner, Haripur of Khyber Pakhtunkhwa (KP) province. There is a long list of management practices (Ahmed and French, 2008) for the control of termites having several environmental concerns (Badshah et al., 2004; Akhter, 2008). Poor knowledge on presence, host and habitat type attacked may also aid in the failure of the control strategies. Because of the presence of the termites in the proposed area, farmers, foresters, and public have unknown annual losses without having any available comprehensive knowledge about the type of species present, host food and habitat. Therefore, the present study was designed to report the diversity of termite's species, genera strength, percent host and habitat attacked in each district during 2016-19 for onward utilization in the management practices by the policy makers.

\section{Materials and Methods}

The present study was conducted in the only three adjoining districts, selected from the three different agro ecological zones of the Khyber Pakhtunkhwa province that are: (i) district Buner (Northern Mountainous (Malakand) Zone) (ii) district Haripur (Eastern Wet Mountainous (Hazara Zone) and (iii) district Swabi (Central Valley plains, Peshawar) (PARC, 1980; Inamullah and Khan, 2015) after studying the literature. All the districts were surveyed from March to November of 2016-19 by dividing it into unit size of $10 \times 10 \mathrm{~km}$ considering the structure/houses, forests, and agriculture field for unbiased culture collection. Overall, 138 samples were collected from the surveyed area by either installing the modified NIFA termaps (containing carton instead of poplar stakes) or by breaking the visible termites' galleries followed by on spot collection (Saha et al., 2016) (Figure 1), in the vails containing $70 \%$ ethyl alcohol for preservation. Identification keys of Roonwal and Chhotani (1989), Chhotani (1997), Maiti (2006) and Manzoor (2006) were used, and specimens were deposited in the Insect Museum, Department of Entomology, The University of Agriculture, Peshawar; Pakistan. GPS device (Garmin e-trex 10) was used for recording colony coordinates. All the missed samples are excluded from the study.

\section{Analysis}

After collection all the data was entered and manipulated in Excel (Microsoft Office 365) and values were calculated through the following equations by following Ravan et al. (2015) and Mandal et al. (2010). For year wise graphical presentation, all the collected samples data was yearly segregated (2016-19) 

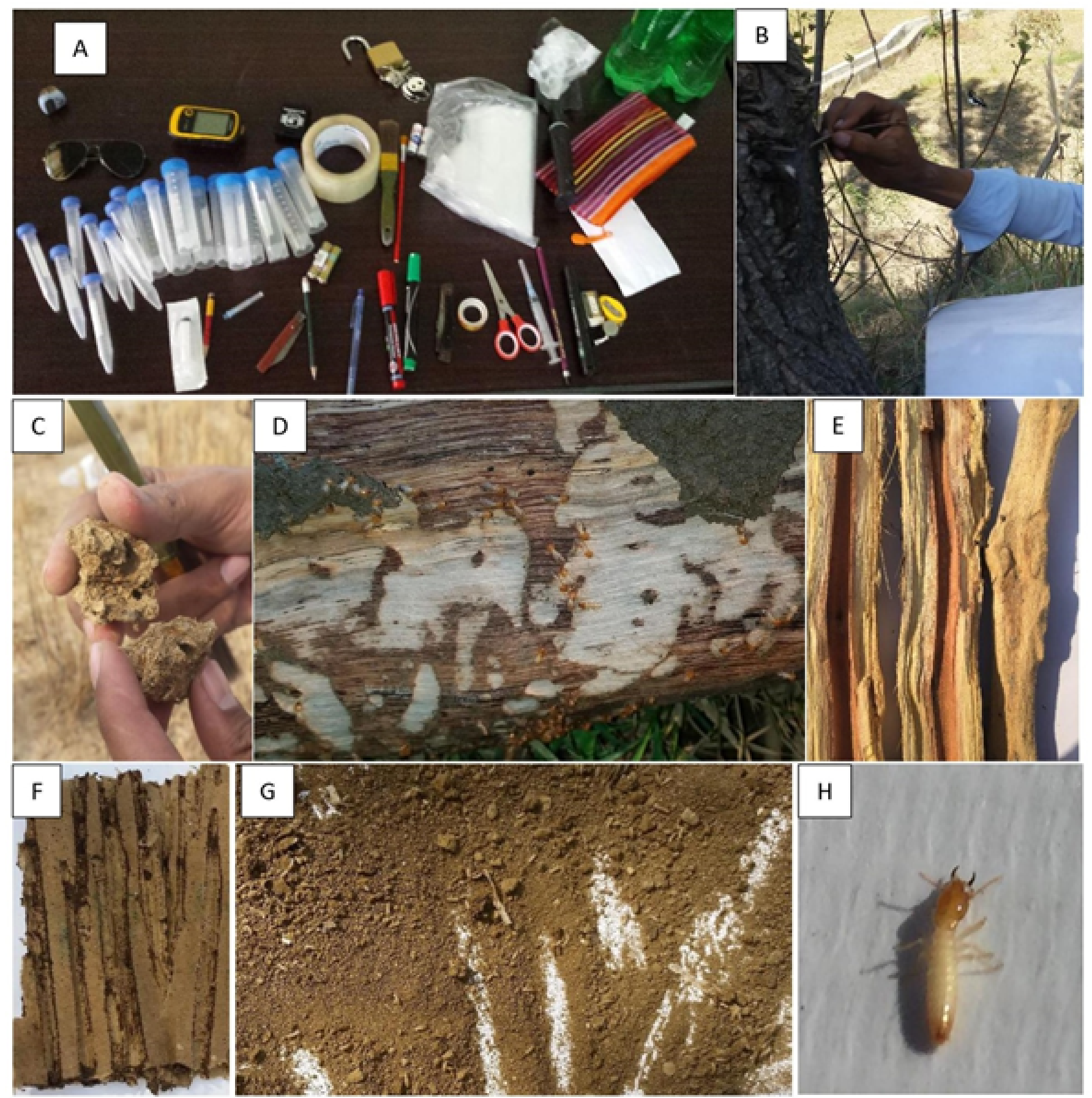

Figure 1: Collection of termites from the studied area during 2016-19, A) Material used, B) Breaking gallaries of termites, C) Breaking mud for on spot collection, D) On spot termites collection from tree trunk, E) Termites feeding on Melia spp. Twigs, F) Carton used in modified NIFA-termap, G) Separation of culture from installed NIFA-termap, $\mathbf{H})$ Separated soldier from collection for storage.

by counting the numbers of samples collected in each year from all the districts. To overview the occurrence and diversity of termites, all samples' data having different type of species were counted per district followed by calculating species strength in the genus.

$\%$ Species strength in genus $=\frac{\text { number of species in the genus }}{\text { Total number of species }} \times 100$

After counting every host food, \% host attacked was calculated by;
$\%$ Host attaacked $=\frac{\text { number of host food source reported }}{\text { Total number of food source }} \times 100$

In order to estimate the habitat attacked by the termites all the recorded samples were segregated into forest, structure and agriculture by counting number of samples collection and \% attacked was calculated by;

$\%$ Habitat attacked $=\frac{\text { number of samples in habitate type reported }}{\text { Total number of samples in all habitat type }} \times 100$

All the data was presented graphically. 


\section{Results and Discussion}

\section{Overview of termite's culture collection}

For successful culture collection, the proposed time is from March to October excluding the monsoon rainfall season for the localities as studies conducted previously in the country. Chaudry and Ahmad (1972) have collected termites' samples without stating the duration and year wise collection plan for the afterward researchers. Figure 2 shows the number of culture collection samples taken during 2016-017, the focus districts were Buner and Haripur. While, in 2017-018 focus districts were Haripur and Swabi. Similarly, in 2018-019 focus district was only Swabi. This validates the presence of termites in the studied area for collection during March to October and $\mathrm{No}^{-}$ vember in case of dry season.

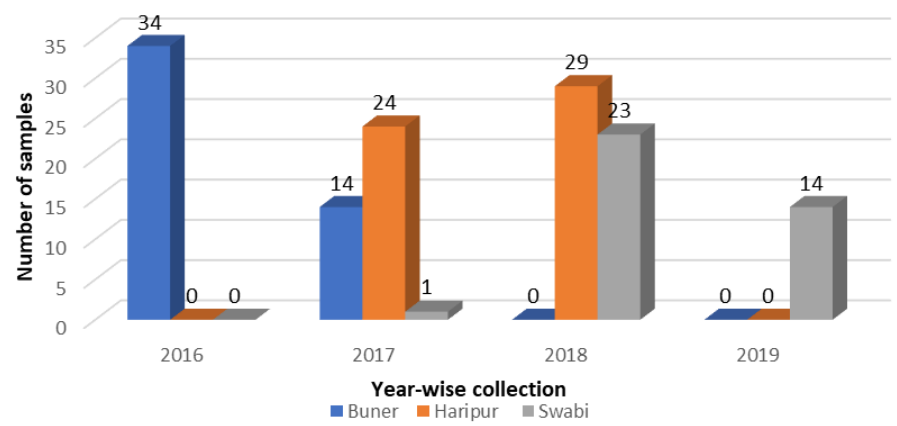

Figure 2: An overview of termite's culture collection over time in the studied area of Khyber Pakbtunkbwa during 2016-19.

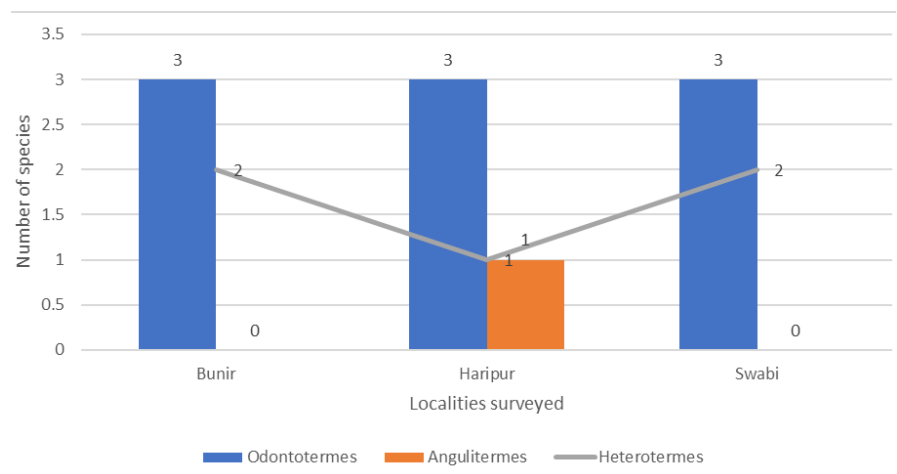

Figure 3: Number of species in the selected districts of various agro-ecological zones of Khyber Pakbtunkbwa, during 2016-19.

Species diversity and genera strength in the various Agro-ecological Zones of the KP

Khyber Pakhtunkhwa (KP) is divided into 04 different Agro-ecological zones by Inamullah and Khan, (2015) in which the studied area was comprised of three districts as discussed earlier. Considering the climatic conditions and crop diversity in the studied area, termites' diversity is obvious. As after studying all the selected districts, it is noted that all districts have equal species number but different species type June 2022 | Volume 38 | Issue 2 | Page 521 during the study period (Figure 3). Comprised of the species from the genera Heterotermes (02), Odontotermes (04) and Angulitermes (01). Heterotermes and Odontotermes are the reported damage causing genera of termites throughout the country (Salihah et al., 2012) including the neighbor districts of the studying areas.

In terms of number of species, genus Odontoteremes is more strengthened (57\%) followed by genus Heterotermes (29\%) and genus Angulitermes (14\%) against the studied areas (Figure 4). Considering the ecological conditions (Financekpp, 2016) of the surveyed area having dry lands with the sub mountainous regions, forests and orchards is supporting the presence of genera Odontoteremes, Heterotermes and Angulitermes as reported by Chaudry and Ahmad (1972), Roonwal and Chhotani (1989), Chhotani (1997), Manzoor (2006), Maiti (2006). While in the surrounding areas, Salihah et al. (2012) have only reported the damages of genus Heterotermes in district Abbottabad, genera Microtermes and Coptotermes in district Attack, genera Microtermes and Odontotermes for Islamabad, Heterotermes, Microtermes and Odontotermes for Rawalpindi, Odontotermes and Coptotermes for Murree hills, Coptotermes for Swat. The variation in the type of species and number of species in genera are also based on ecological conditions, crops and plants diversity, cropping pattern and soil condition in the studied area (Akmal et al., 2014; KP tribune, 2016; GoP, 2017).

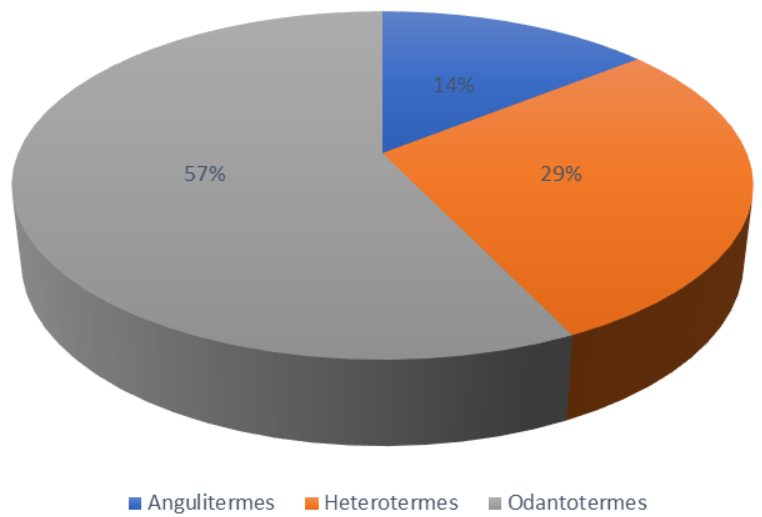

Figure 4: Species strength in different genera of the selected districts of various agro ecological zones of Khyber Pakhtunkhwa, during 2016-19.

\section{Percent host attacked in different Agro ecological zones of $K P$}

Figure 5, shows a comparative status of $\%$ host attacked by different species of termites in the studied area reported for the first time. It reveals that in district Buner wood and Pinus were most attacked while 


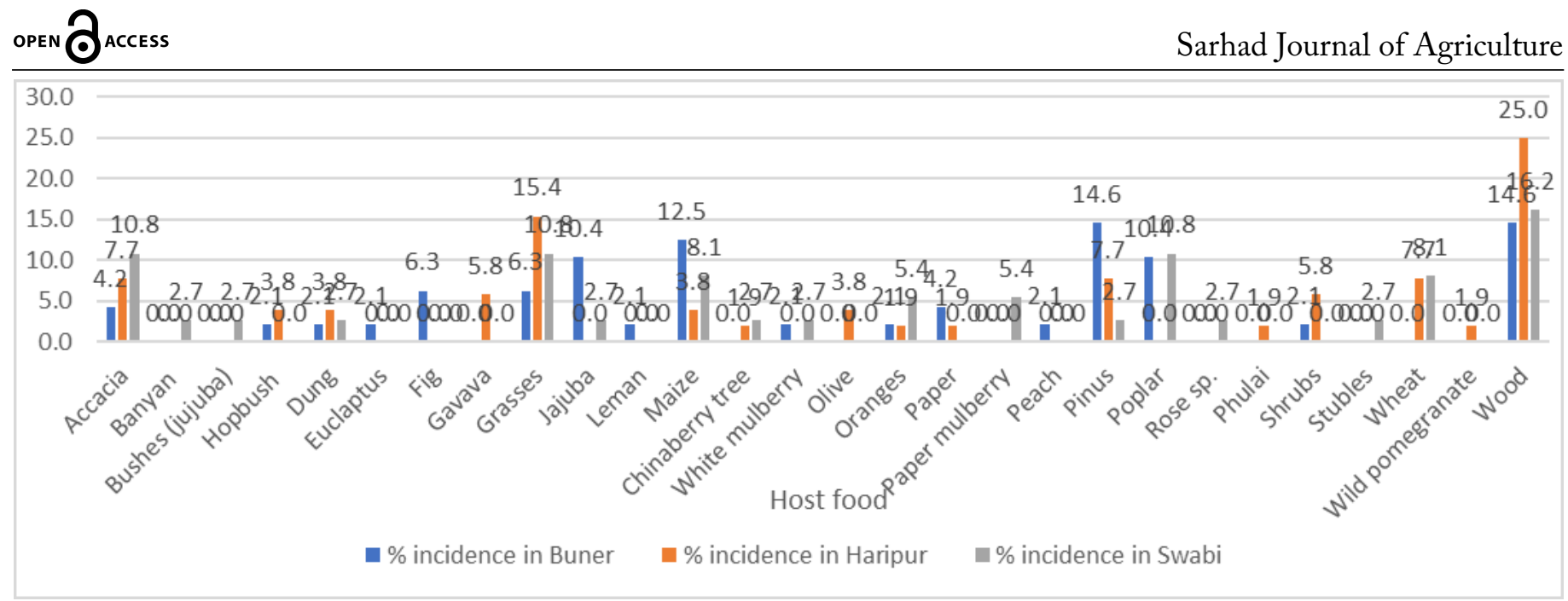

Figure 5: Percent termite's incidence on different host foods in the selected districts of various agro ecological zones of Khyber Pakbtunkbwa, during 2016-19.

wood followed by grasses and acacia was attacked in district Haripur; and maize, Pinus and wood are most attacked in district Swabi. Wood is the structural timber (Pinus spp.) used for indoor construction. Our findings are in line with various researchers (Chaudry and Ahmad, 1972; Manzoor, 2006; Salihah et al., 2012) by reporting different type of host foods including the current host foods from the other parts of the country with different type of termite's species based on the ecological conditions of the area.

\section{Percent habitat attacked by different species of termites in the studied area}

In consideration to the diverse ecological conditions of the study area, a random survey in the different type of habitats (forest, structures, and agriculture) for termite's culture collection during 2016-19 is resulted into an almost similar number of percent attacks for forest in Haripur (46.15\%) and Buner (47.92\%) with lower number of attacks in Swabi (34.21\%). Similarly, $35.42 \%$ of structures are attacked in Buner with $34.21 \%$ attack in districts Swabi and 30.77\% attack district in Haripur (30.77\%). In agriculture, Swabi was maximum percent attacked $(31.58 \%)$ as compared to Haripur (23.08\%) and Buner (16.67\%), represented graphically in the Figure 6. In the current study for the first time the \% habitat attacked is reported for the studied area as earlier to this, other researchers have reported the different type of food sources regardless of habitat type (Chaudry and Ahmad, 1972; Manzoor, 2006; Salihah et al., 2012) for the other parts of the country. Moreover, it was observed that district Swabi have lower forest area, higher area for agriculture land with concrete structures while district Buner have higher forest area, lower area for agriculture land with wooden structures. Similarly, district Haripur have higher forest area and lower area for agriculture land with concrete structures.

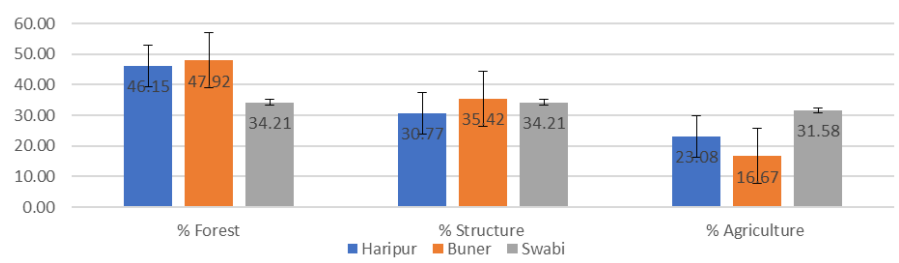

Figure 6: Percent habitats attacked by termites in the selected districts of various agro ecological zones of Khyber Pakbtunkbwa, during 2016-2019.

\section{Conclusions and Recommendations}

Pakistan is a blessed country having diverse ecological conditions from seaside to highest peak of the world. Termites are mostly found in the tropics of the country causing enormous damages to agriculture, forestry, and structures. But no recent data is available about the damages, diversity, host food and habitat for the district Swabi, Haripur and Buner. A total of 05 different type of species belong to 03 genera ( $O d-$ ontotermes, Heterotermes and Angulitermes) are reported for the studied area. Genus Odontotermes is more diverse in terms of number of species than the genus Heterotermes and Angulitermes. Wood, Pinus, grasses and acacia were most attacked host food. In habitat study, forest, structure, and agriculture field was most attacked in Haripur, Buner and Swabi with lower number of attacks in Swabi, Haripur and Buner, respectively. Knowledge about the termite's species, host food preferred/attacked, and preferred/attacked type of habitat will help scientists, farmers, foresters, and policy makers for the successful management of the pests in the studied area. 


\section{Acknowledgments}

The authors are thankful to Higher Education Commission, Pakistan for providing funds to complete this research study under "HEC Indigenous Scholarship Phase-II".

\section{Novelty Statement}

There was no previous record about the species diversity, genera strength, \% host attacked and \% habitat attacked for the studied area. This is a baseline data which will help the scientists, foresters, farmers, and policy makers for the successful management of the termites in the studied area.

\section{Author's Contribution}

Maid Zaman: Conducted the field trail and write the paper.

Imtiaz Ali Khan and Amjad Usman: Designed the experiments and provided technical guidelines.

Ahmad Ur Rehman Saljoqi: Helped in data analysis.

\section{Conflict of Interest}

The author(s) declare(s) that there is no conflict of interests regarding the publication of this article.

\section{References}

Ahmed, B.M. and J.R.J. French. 2008. An overview of termites control methods in Australia and their links to aspects of termite biology and ecology. Pak. Entomol., 30(2): 101-118.

Ahmed, S., T. Mustafa, M.A. Riaz, and A. Hussain. 2006. Efficacy of Insecticides Against Subterranean Termites in Sugarcane. Int. J. Agric. Biol., 8(4): 508-510.

Akhtar, M.S. 1972. Studies on the taxonomy and zoogeography of termites of Pakistan. Ph. D. Thesis. University of Punjab, Lahore.

Akhter, N. 2008. Biodiversity of entozoic flagellates of the Hetrotermesindicola and Coptotermesheimi and the effect of wood, wood extracts and anti-protozoan drug on flagellates. $\mathrm{PhD}$ Thesis. Govt. College University, Lahore. pp. 1-331.

Akmal M., N. Ahmed, A. Khan, F. Bibi and J. Ali. 2014. Climate Change and Adaptation Farmers' Experiences from Rainfed Areas of Pakistan. Study Conducted by Climate Change Centre, The Agricultural University Peshawar.
$14 \mathrm{p}$.

Badshah, H., Farmanullah, Z. Salihah, A.U.R. Saljoqi and M. Shakur. 2004. Toxic effect of Ak (Calotrpisprocera) plant extracts against termites (Hetrotermesindicola and Coptotermesheimi) Isoptera: Rhinotermitidae. Pak. J. Biol. Sci., 7(9): 1603-1606. https://doi.org/10.3923/ pjbs.2004.1603.1606

Chaudry, I.M. and M. Ahmad. 1972. "Termites of Pakistan, Identity, Distribution and Ecological Relationships" Final technical report. Project no. A17-FS-12. Pakistan Forest Institute Peshawar-Pakistan. pp; 1-72.

Chhotani, O.B. 1997. Fauna of India-Isoptera (Termites) Vol. II; Pp; 530.

Eggleton P. 2000. Global patterns of termite distribution. In: Abe T, Bignell DE, Higashi M (Eds) Termites: Evolution, Sociality, Symbiosis, Ecology. Kluwer Academic Publishers: Dordrecht. pp 25-51. https://doi.org/10.1007/97894-017-3223-9_2

Financekpp., 2016. About Education Department. Retrieved on: 16/05/2016, Retrieved from: http://www.haripur.financekpp.gov.pk/ index.php?option $=$ com_content\&view $=$ arti cle\&id $=67 \&$ Itemid $=81$

Ghaly, A. and S. Edwards. 2011. Termite Damage to Buildings: Nature of Attacks and Preventive Construction Methods. Am. J. Eng. Appl. Sci., 4 (2): 187-200. https://doi.org/10.3844/ajeassp.2011.187.200

Government of Pakistan. 2017. Food and cash crops area and production by districts 198182 to 2008-09. Retrieved at: 18/07/2017 Retrieved from: http://www.pbs.gov.pk/ sites/default/files/agriculture_statistics/ publications/area_and_production_by_districts_1981-82to200809/Area\%20and\%20Production\%20By\%20Districts\%20for\%2028\%20 Years.PDF

Hickey, C.D. 2006. Effect of disodium octaborate tetrahydrate in ethylene glycol on consumption and mortality of eastern subterranean termites. M. Sc. Thesis. Florida University of Florida. pp 57.

Inamullah, and A.A. Khan. 2015. "Agro-Ecological Zones of Pakistan" in "Agriculture The Basics", Ikhwan Publisher, Mohallah Jhangi, Qissa Khwani Bazar, Peshawar. pp. 97-99.

Jones, D.T., Robert H.J.V. and P. Eggleton. 2005. Methods for sampling termites. In S. R. Leath-

June 2022 | Volume 38 | Issue 2 | Page 523 
er. (Eds). Insect Sampling in Forest Ecosystems; Blackwell Science Ltd. pp:222.

Kambhampati, S. and P. Eggleton. 2000. Phylogenetics and taxonomy. In: Abe T, Bignell DE, Higashi M (Eds) Termites: Evolution, Sociality, Symbiosis, Ecology. Kluwer Academic Publishers: Dordrecht. pp. 1-23. https://doi. org/10.1007/978-94-017-3223-9_1

Khan, I.A., M. Zaman, R. Akbar, I. Ali, M. Alam, M. Saeed and A. Farid. 2015. Efficacy of single and mixed particles sand size as physical barrier against Heterotermesindicola under laboratory conditions. JEZS. 3(4): 106-109.

Kirton, L.G. 2005. The importance of accurate termite taxonomy in the broader perspective of termite management. In Proceedings of the Fifth International Conference on Urban Pest, 10-13 July, 2005, Suntec, Singapore. pp. 1-7.

Kp, tribune, 2016. Buner Geography. Retrieved on: 12/07/2017, Retrieved from: http://kpktribune.com/index.php/en/disst-buner/buner-geography

Maiti, P.K. 2006. A taxonomic monograph on the world species of Termites of the family Rhinotermitidae (Isoptera :Insecta) Memoirs, Vol. 20 (No.4); 1-272. (Published-Director, Zool. Surv. India, Kolkata)

Mandal, B.K., K. Bashar, A.J. Howlader and K.M.Z. Rahman. 2010. Incidence of termite infestation to tree species in Jahangirnagar University Campus, Bangladesh. Bangladesh J. Life Sci., 22(2): 7-15.

Manzoor, F. 2006. Monograph on Morphometric Studies on the termite genus Odontotermes. Higher Education Commission, Pakistan. pp.
154.

Miller, D.M. 2010. Subterranean termite biology and behavior. Publication 444-502. Retrieved date: $23 / 11 / 2013$, Retrieved from: http://pubs. ext.vt.edu/444/444-502/444-502_pdf.pdf.

PARC, 1980. Agro-ecological zones of Pakistan. Pakistan Agricultural Research Council, Islamabad, Pakistan.

Randall, C.J. 2000. The biology of termites and other wood-destroying pests" In: "Management of wood-destroying pests". Retrieved date: 23/11/2013, Retrieved from: http://www. ipm.msu.edu/uploads/files/TrainingManuals_ WoodDestroying/WoodDestroying_WholeManual.pdf.

Ravan, S., I.A. Khan, F. Manzoor and Z. Khan. 2015. Feeding habitats and wood preferences of termites in Iran. JEZS; 3(5): 20-23

Roonwal M.L. and O.B. Chhotani. 1989. The fauna of India and the adjacent countries Isoptera (termites). 1: 1-695.

Saha, N., P.C. Mazumdar, J. Basak, A. Raha, A. Majumder and K. Chandra. 2016. Subterranean termite genus Odontotermes (Blattaria: Isoptera: Termitidae) from Chhattisgarh, India with its annotated checklist and revised key. J. Threatened Taxa, 8(3): 8602-8610. https://doi. org/10.11609/jott.2654.8.3.8602-8610

Salihah, Z., A. Satar, A. Farid and A.R. Shakori. 2012. Termites of Pakistan and their control. Zool. Soc. of Pak., Lahore. pp. 11-32.

Verma, M., S. Sharma and R. Prasad. 2009. Biological alternatives for termite control: A review. Int. Biodeterioration Biodegradation, 63; 959-972. https://doi.org/10.1016/j.ibiod.2009.05.009 